Para enlazar con este artículo / To link to this article:

http://dx.doi.org/10.14198/fem.2018.32.06

Para citar este artículo / To cite this article:

Gisbert-Alemany, Ester. «El paisaje es quehacer. La creatividad sostenible de las prácticas éticas y afirmativas». En Feminismo/s, 32 (diciembre 2018): 157-179. Dosier monográfico: MAS-MES: Mujeres, Arquitectura y Sostenibilidad - Medioambiental, Económica y Social, coord. María-Elia Gutiérrez-Mozo, DOI: $10.14198 / \mathrm{fem} .2018 .32 .06$

\title{
EL PAISAJE ES QUEHACER. LA CREATIVIDAD SOSTENIBLE DE LAS PRÁCTICAS ÉTICAS Y AFIRMATIVAS
}

\author{
THE LANDSCAPE IS A TASK. THE SUSTAINABLE \\ CREATIVITY OF ETHIC AND AFFIRMATIVE URBAN \\ PRACTICES
}

\author{
Ester GISBERT-ALEMANY \\ Universidad de Alicante \\ ester.gisbert@ua.es \\ https://orcid.org/0000-0002-0612-1159
}

\section{Resumen}

En este artículo se trasladan al español las ideas sobre el paisaje del antropólogo Tim Ingold y se explora sus implicaciones para un urbanismo hecho desde dentro del paisaje. Partiendo de los debates sobre el Landscape Urbanism, el hilo conductor es el desajuste inevitable en la traducción del concepto taskscape. Acuñado en 1993 para redefinir el paisaje como un proceso ontogénico que se desarrolla en el tiempo, fue muy aceptado en diversas disciplinas, pero Ingold rechazó su uso como categoría descriptiva. Evitando la traducción literal como paisaje de tareas, se propone el término «quehacer». Esta traducción permite relacionar su propuesta con el activismo feminista de Rosi Braidotti y Donna Haraway para explorar su potencial político en el urbanismo. En conversación con ellas, y a partir de la discusión del trabajo de varias diseñadoras, se encuentra una alternativa centrada en la vida a la relación entre ecología y creatividad que suele implicar el paisajismo.

Palabras clave: paisaje, taskscape, Landscape Urbanism, activismo feminista, quehacer (CC BY 4.0)

Feminismo/s 32, diciembre 2018, pp. 157-179 


\begin{abstract}
This paper introduces into Spanish the ideas about the landscape of the anthropologist Tim Ingold and its implications for an Urbanism practiced from inside the landscape. Starting from the debates on Landscape Urbanism, the common thread is the inevitable mismatch in the translation of the concept «taskscape». Coined in 1993 to redefine the landscape as an ontogenetic process that develops over time, it was widely accepted in various disciplines, but Ingold rejected its use as a descriptive category. Avoiding the literal translation as «paisaje de tareas», the term «quehacer» is proposed. This translation allows to relate Ingold's proposal to the feminist activism of Rosi Braidotti and Donna Haraway and to explore its political implications in Urbanism. In dialog with them, and with the discussion of the work of several designers, there is an alternative focused on life to the relationship between ecology and creativity that is often involved in landscape design.
\end{abstract}

Keywords: Landscape, taskcape, Landscape Urbanism, feminist activism, «quehacer»

\title{
1. INTRODUCCIÓN
}

El objetivo de este artículo es trasladar a la lengua española las ideas sobre el paisaje del antropólogo Tim Ingold y, utilizando creativamente los desajustes inevitables en cualquier traducción, ponerlo en relación con las aportaciones recientes del pensamiento feminista para explorar las implicaciones de este encuentro para una práctica afirmativa de un urbanismo hecho desde el paisaje.

Este viaje conceptual lo estructura la discusión de la traducción de este concepto, taskscape, al español. El término fue introducido en 1993 por el antropólogo Tim Ingold en el artículo «The Temporality of the Landscape», que intentaba unir las prácticas de la antropología sociocultural y la arqueología en una nueva forma de entender el medio ambiente que superara la dicotomía entre naturaleza y cultura (Ingold, Temporality 152). Repetidamente, Ingold ha rechazado que se utilice el taskcape para hacer descripciones de las actividades y usos en un lugar. Además, lamenta haber contribuido a la proliferación de términos compuestos para referirse a distintos aspectos del paisaje (-scapes) que, según él, reducen situaciones relacionales o sensoriales a la idea de proyección de la forma (Janoski e Ingold 10-11). A pesar de usarse para tratar sonidos, olores (Helmreich) y otras sensaciones hápticas,

Feminismo/s 32, diciembre 2018, pp. 157-179 
según Ingold estos términos parciales relacionan su significado con la etimología del griego clásico skopein (mirar, apuntar una flecha), en lugar de relacionarlo con la raíz germánica sceppan o skyppan (dar forma). La segunda es la preferida por Ingold, que insiste en rechazar la idea de proyección de la forma (Ingold et al. «Diálogos»; Ingold, «Taking» 24). Los otros términos fortalecerían el régimen escópico prevalente en nuestras formas de representación de imágenes, en general, y también en el paisajismo. Según Jay (1), este régimen es heredero de la perspectiva renacentista de Alberti y culmina en el cine. Pero se caracteriza aún más por la ausencia de lo real que por la distancia que nos separa de ello, es decir, por convertirnos en espectadores cambiando nuestra forma de percepción de una posición activa a otra pasiva y contemplativa.

Como veremos, el objetivo de Ingold es precisamente el contrario, recortar la distancia con lo representado al ponernos en movimiento e invitarnos a recorrerlo y percibirlo desde dentro y cerca. Por ello, evitando una traducción literal como paisaje de tareas, que además tendría sus propias connotaciones localistas derivadas de la evolución de la palabra pagus en país, se utiliza el término «quehacer». Esta palabra significa, literalmente, tarea o tareas que han de hacerse, y permite aprovechar el desplazamiento de significados que supone cualquier traducción para intensificar la propuesta de Ingold al ponerla en conversación con las ideas de las pensadoras feministas Rosi Braidotti y Donna Haraway. Con ello, nos proponemos explorar el potencial de este concepto para hacer una aproximación creativa, ética y afirmativa en el urbanismo hecho desde el paisaje.

Para ello, comenzaremos situando el punto de partida de este artículo en los últimos debates alrededor del paisaje en la disciplina urbanística. En su teoría del paisaje como urbanismo, el arquitecto paisajista Charles Waldheim explica que, cuando a partir de los 90 el urbanismo como disciplina tomó el paisaje como categoría de trabajo teórico y práctico, éste fue una manera de ocupar el vacío creado, por un lado, por el giro del diseño urbano hacia el neotradicionalismo del town planning y, por otro, por el giro del planeamiento hacia un modelo de ciencia social que tiene más que ver con la planificación regional (Waldheim 4). Como ocurría con las ciencias sociales, el paisaje fue una forma de escapar del determinismo ecológico de la primera ola de estudios ambientales. Esto es especialmente visible en el trabajo de James

Feminismo/s 32, diciembre 2018, pp. 157-179 
Corner, uno de los últimos héroes de la arquitectura paisajista americana que fue discípulo de Ian McHarg (autor en 1971 del libro fundacional para el enfoque ecológico Diseñar con la naturaleza). Ya en 1997, Corner se preguntaba:

si pudiéramos concebir que la landscape architecture fuera un agente activo en el juego de la intervención evolutiva, ¿cómo tendríamos que interpretar la ecología y la creatividad en la práctica del diseño? (258).

En sus escritos y trabajos, Corner ha intentado responder a esta pregunta separándose del diseño de ecosistemas para recuperar el paisaje como "proyecto cultural».

Después de todo, no hay nada natural en el paisaje: aunque el paisaje invoca la naturaleza y se relaciona con los procesos naturales a lo largo del tiempo, en primer lugar, es un constructo cultural, un producto de la imaginación. Los paisajes se imaginan y representan inicialmente en imágenes y palabras, se modelan en miniatura en los jardines y, finalmente, se codifican en el planeamiento, diseño y construcción del entorno a gran escala (7-8, traducciones de la autora).

Esta respuesta parte de un intento de rechazar la separación entre naturaleza y cultura compartida por el resto de autores discutidos en este texto y legitima su conexión. Sin embargo, no puede evitar reproducir esa línea divisoria al situar el paisaje en la tradición disciplinar del paisajismo como forma de arte y profesión liberal. Nuestra hipótesis es que el paisaje como «quehacer» puede responder de forma alternativa a la pregunta de Corner. Para exponerla y comprobarla, primero se desarrollan las ideas de Ingold sobre el paisaje a través de la discusión de la traducción del término taskscape como «quehacer», apoyándonos en trabajos posteriores suyos y de otros autores. A partir de esta discusión, se establece una relación entre el «quehacer» y el activismo que promueven Braidotti y Haraway. Estas autoras feministas pueden guiarnos para explorar las implicaciones políticas y éticas del «quehacer». A través de algunos ejemplos que siguen la estela del tipo de prácticas creativas en las que los tres autores apoyan sus desarrollos conceptuales, se intenta mostrar cómo la ética afirmativa consigue, por un lado, redefinir la ecología y la creatividad desde lo estético, y por otro, mantener al arquitecto urbanista dentro del mundo y no fuera de él. Así, las prácticas creativas urbanísticas pueden participar del mundo en lugar de mantener la distancia típica del planeamiento urbano y, además, ponerse al servicio de

Feminismo/s 32, diciembre 2018, pp. 157-179 
la reinvención de los quehaceres de personas, cosas y lugares para mantener la vida en el Antropoceno. Finalmente, poniendo estos ejemplos de nuevo en relación con el mundo del Landscape Urbanism, se explora cómo podría redefinirse la práctica del paisajismo para ofrecer una alternativa a cómo los urbanistas entendemos nuestra relación creativa con el entorno. En lugar de un proyecto que sale de la mente de un diseñador, el paisaje vendría a estar conformado por las formas emergentes de los ritmos de todos los quehaceres de personas y cosas que se entretejen en un entorno, incluido el del diseñador.

\section{EL PAISAJE ES QUEHACER}

En el artículo «The temporality of the Landscape», Ingold comienza definiendo el paisaje que pretende temporalizar. Para ello explica lo que el paisaje no es: no es tierra, entendida como suelo cuantificable e intercambiable; tampoco es naturaleza, como algo que podamos separar de las actividades humanas; y, finalmente, no es espacio, en el sentido de un lugar de representación abstracta que podamos visualizar desde fuera (153-7).

Así, el paisaje aparece como un proceso. Una idea que comparten Corner y Waldheim cuando discuten los proyectos pioneros del Landscape Urbanism como los de Koolhaas y Tschumi para el Parque de la Villette. Sin embargo, para Ingold la temporalidad aparece con el patrón de actividades del habitar que se despliega alrededor del practicante activo y en movimiento. Es un paisaje material y temporal que, a través de la percepción, une los diversos ritmos de las actividades de otros seres vivientes también en movimiento y, como veremos más adelante, también los elementos atmosféricos en constante cambio. Este conjunto de actividades con ciclos diversos es el que Ingold nombra con el término taskscape. Lo traducimos como «quehacer», pues Ingold da a entender que, si quisiéramos entenderlo como un panorama, éste sólo se abre al practicante a través de las tareas que él mismo realiza a lo largo de su camino al involucrarse perceptiva y materialmente en el tejido activo del mundo. Al contrario que la tradición disciplinar del paisaje en arquitectura y urbanismo, que pone el énfasis en la forma cristalizada, el quehacer pone el énfasis en el movimiento.

Desde la publicación en 2000 del volumen de artículos compilados The Perception of the Environment, que incluía 'The Temporality of the Landscape', 
Ingold apenas se refiere al taskscape y sólo lo hace cuando está específicamente hablando de tareas, prácticas y destrezas (Being 59, 61,16) y para explicar por qué no debería usarse. Desde entonces Ingold utiliza, en cambio, la idea de tarea (task) para especificar la temporalidad a la que se refiere. Pero ya entonces explicaba que no se trata del tiempo cronológico o histórico, sino de la «duración» bergsoniana ( «Temporality» 159), ese tiempo en el que se desarrollan las tareas, en el que las cosas crecen y evolucionan creativamente. Una vez definido así, nos decía, el propio paisaje es temporal. Así, el término taskcape ya no es necesario. Ingold explicaría después («Taking», «Diálogos») que sólo lo incluyó para poder desarrollar este argumento por el que el paisaje deja de ser un telón de fondo para las actividades, o una superficie que un relato cultural cubre de significado. El paisaje es un verbo, un proceso activo en el tiempo. El quehacer es el paisaje.

¿Por qué entonces insistir en la traducción de una palabra que el propio creador rechaza ahora? Los proyectistas del Landscape Urbanism son conscientes de la imposibilidad de cristalizar la forma de un paisaje y proyectos como los de La Villette son marcos estratégicos de acción, pero se quedan fuera del cuadro y proponen las «reglas del juego». En los casos más inspirados, como el Parque del High Line diseñado por Corner junto con los arquitectos Diller, Scofidio y Renfro, estas reglas incorporan los movimientos de lo que ocurría allí antes de que ellos llegaran (Corner 341-9). Pero la ausencia de lo real, heredera del régimen escópico del que nos hablaba Jay, se mantiene. Esto es debido a que el paisaje al que estos paisajistas se refieren y con el que trabajan, sólo se remonta a la pintura de paisajes del XVII, cuando la división entre naturaleza y cultura ya había arraigado en las formas de pensar de la Era Moderna (Waldheim 160-75). En este artículo se comparte la idea del paisaje como una relación estética con el entorno, pero se problematiza la identificación de esta imaginación del paisaje con las herramientas y prácticas de las disciplinas urbana y arquitectónica modernas. Como muestra Ingold a través de la discusión etimológica de la palabra landscape comentada anteriormente, el paisaje existía antes de que sus pintores usaran el término. De hecho, según nos explica el geógrafo Fernández-Christlieb (60-61), en las lenguas latinas la palabra mantiene aún sus connotaciones locales y agrícolas: paesaggio, en italiano, paysage en francés y paisagem en portugués, comparten todas la raíz latina pagus o pago (distrito agrícola y pueblo o aldea rural).

Feminismo/s 32, diciembre 2018, pp. 157-179 
Las personas y cosas que habitaban un lugar hacían paisajismo antes de que Brunelleschi redescubriera la perspectiva en el Renacimiento, de que Alberti la convirtiera en la herramienta que define el trabajo del arquitecto y en la que lo encuadra en el régimen escópico de la pintura, la fotografía y el cine, el mismo régimen que ahora se le supone al paisaje. Antes de todo eso, el «quehacer» era el paisaje.

De ahí la importancia para el urbanismo hecho desde el paisaje de la propuesta de Ingold y nuestra insistencia en incorporar tanto este sentido a la palabra paisaje como el «quehacer» entre nuestras herramientas conceptuales. Frente a la visión panorámica del -scape, que nos saca fuera del mundo, el «quehacer» pretendía insertarnos dentro de una ecología de prácticas (Stengers). Cuando los arquitectos y urbanistas teorizan sobre el paisaje, son víctimas de un desplazamiento hacia el exterior del mundo. Esto ocurre porque insisten en buscar el origen de las prácticas paisajísticas en la tradición disciplinar.

La palabra «quehacer» es importante porque, a diferencia del compuesto en inglés taskscape, saca al paisaje de la tradición pictórica y lo lleva más atrás en el tiempo. Refiriéndose a un trabajo hecho «desde cerca, involucrando al cuerpo de forma inmediata, muscular y visceral» con los materiales. Lo contrario de la mirada intelectualizada, distante y desafectada que el paisaje nos sugiere hoy en día, en su sentido medieval, dar forma a la tierra es trabajar en ella («Taking» 24).

\section{APRENDER EL PAISAJE DESDE DENTRO}

Para ilustrar cómo se hace el paisaje desde dentro, Ingold termina su artículo de 1993 con un ejemplo práctico. A partir de la pintura de Bruegel, «La cosecha» (1565), es capaz de convertir un paisaje estático (y probablemente fruto de una idealización) en algo vivo, simplemente con sus palabras. Lo hace con un pequeño truco similar al del personaje cinematográfico Mary Poppins (Walsh et al.). En la escena del parque, la institutriz mágica y los niños se meten dentro del paisaje pintado en el suelo por un artista callejero. De la misma forma, en lugar de dejarnos fuera mirando la pintura para discutir su valor estético o sus implicaciones históricas, Ingold nos mete dentro de ella y va dirigiendo con sus palabras nuestras sensaciones y percepciones

Feminismo/s 32, diciembre 2018, pp. 157-179 
hacia los distintos quehaceres de campesinos, cultivos, árboles, montañas y caminos. Oímos, probamos, olemos, vemos y tocamos. Así, aprendemos ese paisaje en movimiento.

Ingold nos dice que, para abrir el paisaje, para poder actuar en ese entorno, tenemos que educar nuestra atención y colocarnos como aprendices de todos los seres y flujos de actividad que nos encontramos. Implicarnos «perceptualmente con un entorno que está en sí mismo preñado del pasado» («Temporality» 153) y del futuro, pues la asimilación de todas esas tareas ya realizadas nos permite seguir realizando nuevas ( Creatividad»5). Paseamos por el quehacer como el cazador novato, que «viaja a través de la región con sus mentores, y mientras pasa, le son señalados rasgos específicos. Otras cosas las descubre por sí mismo en el curso de las exploraciones, observando, escuchando y sintiendo» («Temporality»153).

Con este enfoque, Ingold consigue demostrar la afirmación con la que comenzó el artículo: el arqueólogo y el antropólogo, y el arquitecto añadiríamos nosotros, comparten, junto con el habitante del lugar, pasado o actual, la misma tarea en el paisaje, todos están implicados perceptualmente en él, aunque cada uno tiene reglas y métodos distintos para hacerlo, y también distintas formas de explicar el conocimiento que desarrollan. Desde los mitos del nativo indígena hasta los informes de campo del arqueólogo o los dibujos del paisajista, los relatos del habitante experimentado orientan la atención del aprendiz. Todas las prácticas suponen un proceso de educación de la atención, todas son formas de habitar («Temporality» 152-3).

Estos relatos no son descripciones objetivas, académicas o cronológicas del entorno. Su «verdad» es la de reconstruir el quehacer al mismo tiempo que se lo conoce. Lo que tienen en común es que, al mostrarlos o contarlos, transmiten un conocimiento a sus aprendices o pares. Pues contar un relato es «una forma de orientar la atención de los oyentes o lectores. Una persona que puede 'contar' es alguien cuya percepción está sintonizada para recoger información en el ambiente que otros, menos hábiles en las tareas de percepción, pueden perderse, y el narrador, al hacer su conocimiento explícito, conduce la atención de su audiencia a lo largo de los mismos caminos que la suya» («Temporality»153).

La idea de poner en el centro al habitante activo, aprendiz en la transformación de un paisaje siempre cambiante, es una constante en el trabajo de

Feminismo/s 32, diciembre 2018, pp. 157-179 
Ingold. Desde sus primeros trabajos de campo y publicaciones sobre cazadores y pastores circumpolares, hasta sus escritos sobre evolución y prácticas creativas, esta idea culmina con la publicación de su libro sobre la antropología como educación (Anthropology and/as Education). Creemos que esta perspectiva de aprendizaje es clave para las disciplinas prácticas y creativas y, especialmente, para la arquitectura y el urbanismo, dedicados a transformar el entorno de tantas vidas ajenas desde la sensibilidad y la percepción propias. Por eso se propone explorar el potencial de sus ideas sobre el paisaje para repensar la práctica del urbanismo. Pero, en lugar de utilizar sus conceptos teóricos como categorías descriptivas o marcos de trabajo, un camino que el propio Ingold ha rechazado, se propone tomar su ejemplo en la redefinición de la antropología como educación y ponernos manos a la obra en la indagación de los futuros posibles de nuestro propio quehacer como urbanistas (Gisbert-Alemany).

\section{EL PAISAJE HAY QUE HACERLO: LA ÉTICA AFIRMATIVA}

La siguiente gran colección de ensayos de Ingold se publicó en 2011 con el título Being Alive. En su introducción, Ingold explicaba que todo su trabajo hasta el momento podía entenderse como un intento de responder a la pregunta «qué supone decir que los seres humanos son los productores de su propia vida» (Being 4). No es casualidad que Ingold cite en su siguiente libro al filósofo español Ortega y Gasset:

lo único que nos es dado y que hay cuando hay vida humana es tener que rehacérsela, cada cual la suya. La vida es un gerundio y no un participio: un faciendum y no un factum. La vida es quehacer. La vida, en efecto, da mucho quehacer (Ortega y Gasset 32-3; en Life 118).

Al contrario que el término en inglés, «quehacer» no es una palabra inventada, tiene gran tradición filosófica. O, mejor dicho, si nos convence la propuesta de Ingold de que la antropología es «filosofía con la gente incluida en ella» ( "philosophy with the people in»), tradición antropológica, es decir, de la filosofía arraigada en la vida. Nosotros quisiéramos que pudiera hacerse también un urbanismo así y el «quehacer» es una palabra cotidiana que nos pone en movimiento, nos invita a remangarnos la camisa y empezar a trabajar. Como la vida, el paisaje hay que hacerlo.

Feminismo/s 32, diciembre 2018, pp. 157-179 
A través de esta idea de producción activa, se relacionará su trabajo con las ideas de las pensadoras feministas Rosi Braidotti y Donna Haraway, que prefieren hablar de la «reproducción de la vida». Es una unión algo arriesgada, pues Ingold responde al prototipo de académico blanco y occidental heredero del humanismo que ellas critican y sus textos dejan ver cierta nostalgia de mundos pasados que puede rechinar con las referencias futuristas y el activismo político de ambas autoras. Sin embargo, como dice Rosi Braidotti al evocar sus propias referencias, «la cuestión es entender si... puede(n) ser una fuente de inspiración capaz de potenciarnos o no». (D)esobedecer con alegría y traicionar con amabilidad y decisión» (Política 72). Animados también por Rolando Silla que, al traducir a Ingold, propone «canibalizarlo, (...) hacerlo nuestro» (17), pretendemos aprovechar el desplazamiento de significados que supone la traducción de taskscape como quehacer para enfatizar ciertos aspectos de la propuesta en los que los tres autores coinciden, como entender la vida más allá de lo humano, la centralidad del cuerpo, la admiración por el artesano materialmente sintonizado con un mundo asombroso, la predilección por el tejer como categoría primaria del hacer y la redefinición a través de su práctica de la globalización. Además, como se ha comentado, este encuentro permite también incorporar otros aspectos al significado de «quehacer»: la idea del cuidado para la reproducción de la vida, la orientación hacia el futuro y las implicaciones políticas de la práctica.

Así, empezamos este encuentro volviendo a la idea de producción implícita en el «quehacer» de Ingold. La producción, para él, es equivalente al habitar: «no comienza aquí (con una imagen preconcebida) y termina allí (con un artefacto terminado) sino que está pasando continuamente» (Perception 205, en cursiva en el original), nos comenta al señalarnos a uno de los campesinos que está cortando una hogaza de pan en el cuadro de Bruegel y que le sirve también para poner el cuerpo activo en el centro de sus ideas sobre el paisaje. También para Braidotti la clave de las prácticas afirmativas se sitúa en el cuerpo. Una vez reunido en él todo lo que hay, y sin más diferencias entre naturaleza y cultura o cuerpo y mente, Braidotti va más allá del feminismo clásico, que reconoce «las diferencias específicas de cada cuerpo», para «identificar las zonas de contacto y relación que median entre nuestros cuerpos y el mundo entero» (Política 24-31). El gesto de cortar el pan sería sólo uno de tantos entretejidos en los ciclos de la transformación del trigo.

Feminismo/s 32, diciembre 2018, pp. 157-179 
Esa hogaza nos hace pensar en el sembrado, la nutrición de las plantas por el sol y tantas otras actividades más allá de las que vemos en el cuadro, como el transporte de los haces de trigo por los caminos hasta el molino, donde se convertirá en harina con la fuerza del viento y los animales. Luego hasta al pueblo, donde alimentará a pescadores, bestias y pájaros y se transportará, quizá, a otros países, junto con lenguas, costumbres e, incluso, junto con ratas. Con Braidotti, podemos entender ese cuerpo que come como una entidad que habita distintos husos horarios a la vez y que es animada por diferentes velocidades y una variedad de relojes internos y externos que no necesariamente coinciden (Between 10).

También Ingold va más allá de la afirmación de la diferencia de cada cuerpo: ha renegado de la antropología entendida como descripción etnográfica que nos ofrece un catálogo de estilos de vida puestos en contexto (Being 229-242). El objetivo de su antropología es, como el de la ética afirmativa de Braidotti, ponernos en conversación con prácticas alternativas a las nuestras para aprender unos de otros a vivir juntos. En el caso de Braidotti, el afecto y el deseo son la potencia de producción de vidas como «subjetividades nómadas y libres capaces de autodeterminación y deseosas de participación política» (Política).

Esto último se entiende bien con la mención anterior a los desfases de velocidad. Esta sugerencia a lo desfasado nos interesa especialmente de la epistemología feminista de Braidotti. Aquello que no está sincronizado, que parece no encajar o funcionar bien, siempre se ha entendido en las prácticas de diseño como una fuente de creatividad. Al fin y al cabo, si todo está bien, ¿para qué necesitamos a un diseñador?

El geógrafo Paul Harrison hizo una crítica de las teorías de la práctica de Ingold precisamente a partir de esta idea de desajuste. Prestó atención al único personaje que Ingold nos decía que no estaba sincronizado con el «quehacer» del paisaje que le rodeaba: el campesino que duerme en la posición central del cuadro le parecía a Ingold «desencajado». Profundamente dormido, este hombre no podía estar atento a los ritmos del «quehacer», las ideas de capacidad y destreza típicas en el pensamiento de Ingold no parecen ser categorías adecuadas para entender la relación de este personaje con su entorno. Harrison quiso hacernos pensar cómo cambiaría nuestro entendimiento de la

Feminismo/s 32, diciembre 2018, pp. 157-179 
práctica si ese personaje dormido fuera el modelo con el que pensamos toda relación con el entorno (1000-4).

Como Harrison, Braidotti y Haraway ven en este desfase algo más que una oportunidad creativa de diseño. No se trata de arreglar el desajuste y devolver a cada cual a sus funciones. Lo diferente y desalineado es una oportunidad para la acción política que afirma otras formas posibles de vida. Es por esto por lo que es más fácil imaginar el futuro acompañados por Braidotti y Haraway que por Ingold. Aunque la imaginación y la creatividad hayan tenido un papel central en sus reflexiones («Shape»), faltan las propuestas e imágenes concretas que nos muestren futuros deseables. Centrado en el momento creativo en sí, no se ha dedicado ni a la ficción ni a la profecía que Haraway ha aprendido de lo que ella llama «SF», para referirse tanto a la ciencia ficción como a la fabulación especulativa (Staying 2). Necesitamos esta «energía de la pensabilidad del futuro» para «entender en qué medida nuestros deseos (de transformación) son sostenibles» (Braidotti, Política 78-80).

\section{ALGUNAS PRÁCTICAS CREATIVAS ÉTICAS Y AFIRMATIVAS}

Por lo expuesto en el anterior epígrafe, a partir de aquí seguirá la conversación entre los tres autores discutiendo ejemplos de prácticas de arquitectos y diseñadores que parten de sujetos y prácticas vulnerables para imaginar futuros inesperados. Al fin y al cabo, consideramos que la posibilidad del encuentro entre estos tres autores de trayectorias tan dispares se debe a la admiración que todos demuestran en sus textos y proyectos de investigación por aquellos practicantes que consiguen estar sintonizados con el mundo de los materiales a través de un arte. Haraway (Companion), en su casa, en sus entrenamientos con su perro, Ingold (Making) con los cazadores y recolectores en sus talleres de artesanía, y Braidotti (Política) bailando mientras escucha la música de las Pussy Riot. Se pretende seguir su ejemplo de humildad al ponerse al lado de estos animales o artesanos, dentro de sus mundos. Cuando escriben sobre ellos, siempre lo hacen como sus aprendices, no como descriptores desafectados de sus realidades. Lo que tienen en común las tres propuestas es, en definitiva, el asombro por el mundo, incluso en su estado más descompuesto, y el deseo de encontrarse activamente con él.

Feminismo/s 32, diciembre 2018, pp. 157-179 


\subsection{En un mundo vital y atmosférico}

Volvamos entonces a la crítica de Harrison, para Ingold el personaje dormido fue, en su revisión del concepto taskscape en 2017, el punto de partida para explicar el rumbo que su trabajo había tomado a partir de 2000. Como veíamos antes, para Ingold la participación en el mundo se entreteje a partir de la percepción del habitante activo. Pero decir que la experiencia sensorial del mundo es encarnada no significa que esté condenada a tener los pies en el suelo. Es en las turbulencias del weather-world (que puede traducirse como «mundo atmosférico», pero se pierde la cotidianeidad de la palabra weather, que en español se traduciría como «tiempo» llevando a equívocos) donde respiramos, donde pensamos y soñamos como hace este personaje de Bruegel.

La luz, el sonido y el sentimiento desprenden nuestras amarras igual que el viento desgarra las ramas de los árboles arraigados en la tierra. Lejos de plegarse dentro del cuerpo -como sugiere el concepto de encarnación- toman posesión de él, arrastrando el cuerpo en sus corrientes. Así, al estar inmerso en los flujos de un medio, el cuerpo es iluminado, sonorizado y cautivado (Being Alive 134-5)

Otra de las razones por las que abandonó el término taskscape es porque no veía cómo podría aplicarse a medios tan fluidos como el mar o el aire. El pescador que trabaja en el mar y el pájaro que vuela en el aire tienen también su «quehacer» en estos medios fluidos. Frente al taskscape, pensar el paisaje desde sus cualidades atmosféricas conecta con las preocupaciones posthumanas de Haraway (Staying) y Braidotti (Posthumano).

Vemos este mundo atmosférico en acción en los libros Delta Primer, a field guide to the California Delta y Los mismos paisajes, de las paisajistas Jane Wolff y Teresa Galí-Izard respectivamente. Ambas se presentan como guías de campo de los quehaceres del agua, las esclusas, los animales, las personas y las plantas en los territorios que estudian. Son guías a las que otro habitante o diseñador podría añadir sus patrones propios o aprendidos y que permiten imaginarnos en el quehacer de reconstruir estos paisajes. Demuestran ambas una cercanía y generosidad en el relato que se echa de menos en los paisajistas abanderados del Landscape Urbanism.

Su sensibilidad por el weather-world nos muestra cómo el paisaje, entendido como quehacer, puede servirnos para prestar atención a los patrones

Feminismo/s 32, diciembre 2018, pp. 157-179 
rítmicos del mundo. Aquello que la filósofa Erin Manning ha llamado weather patterns (63-65) y que, enlazando con el pensamiento posthumano de Braidotti y Haraway, nos permite maravillarnos con las variaciones del mundo que no están sujetas a los dictados de los humanos. El «quehacer» así entendido, como los conceptos de zoe de Braidotti (Posthumano) y la gaia de ciencia ficción de Haraway (Staying), rezuma vitalismo:

la distinción entre lo animado y lo inanimado parece disolverse. El mundo mismo adquiere el carácter de un organismo, y los movimientos de los animales - incluyéndonos a nosotros los seres humanos - son partes o aspectos de su proceso vital (Lovelock, 1979). Esto significa que, al habitar en el mundo, nosotros no actuamos sobre él, o le hacemos las cosas a él, sino que avanzamos con él (Perception 200).

\subsection{En un mundo sin refugios}

La vulnerabilidad de ese personaje dormido en el centro del cuadro nos lleva también a las reflexiones sobre la vulnerabilidad de la vida a partir del Antropoceno que Braidotti y Haraway han explorado en su trabajo. Para Haraway, el Antropoceno señala más un evento límite que una época. El momento en que la naturaleza deja de salirnos barata y estar disponible para rehacer mundos. A partir de ahora, en la prometedora y monstruosa época que ella llama el Chthulucene (Staying 99-103), las prácticas que necesitamos son las «artes de vivir en un planeta dañado» (Tsing en Staying 136). Ambas autoras nos urgen a avanzar sin nostalgia y empezar a construir, cuanto antes, los nuevos refugios para los refugiados, humanos y no humanos, que están viendo sus paisajes destruidos por el Antropoceno. Al situarse críticamente en ese mundo tecnológico, económico y social, Haraway y Braidotti, son capaces de afrontar escalas globales a las que no se accede fácilmente con el trabajo de Ingold. El reto es hacerlo precisamente desde la política de la vida cotidiana.

Este reto está siendo desarrollado por investigadoras y diseñadoras como Raquel Noronha, en correspondencia con artesanos indígenas en Brasil. La propia práctica de diseño de estudiantes y artesanos se toma como el lugar central desde el que montar un nuevo sistema de parentescos (Staying 99-103), no metafórico sino material (Política 71). Noronha explica, por ejemplo, cómo la expansión del negocio agroindustrial en el norte de Brasil impide a los indígenas mantener la relación tradicional con el territorio de

Feminismo/s 32, diciembre 2018, pp. 157-179 
su quehacer. Sin acceso a los recursos que antes disponían cerca, el plástico ha sustituido a la madera y a las fibras de palma en algunas de sus artesanías y, paradójicamente, es el uso de este material el que les impide mostrar su trabajo como parte de la declaración de identidades auténticamente indígenas que fortalecería legalmente sus derechos sobre ese territorio (Noronha 132). Lo interesante es que, en este proceso de cambio de material, habían olvidado su relación tan cercana con el paisaje. Como parte de su quehacer en este lugar, Noronha se encargó de volver a traer el material tradicional a unos talleres realizados con sus estudiantes y los indígenas. Al trabajar de nuevo con el material de la palma, se empezó a recordar ese parentesco con el paisaje. El uso de la palma para su arte desplegaba su quehacer por el territorio cercano y construía un paisaje y un ciclo que nos recuerdan al de los cosechadores de Bruegel. El uso del plástico también genera un parentesco, sin embargo, es un parentesco extraño que Haraway llama oddkin (Staying 99): con él, el quehacer de los indígenas ya no forma un ciclo que podamos considerar virtuoso, sino uno que incluye la extracción petrolera por el mismo tipo de empresa que les ha expulsado de sus territorios y con las que están, quieran o no, también emparentados.

Este ejemplo resuena con la propuesta de estos tres pensadores de que los seres somos nuestro devenir: si somos producidos tanto como producimos, la exploración creativa de nuevas relaciones con los materiales del quehacer puede cambiar profundamente cómo entendemos el paisaje. Otro trabajo que nos habla de este quehacer desde las vidas y las prácticas de personas y cosas inadaptadas, aquellas cuyo quehacer ya no está en armonía con el mundo contemporáneo, es el trabajo de la arquitecta Marina Fernández Ramos con mujeres mayores y jóvenes del pueblo Valverde de la Vera, en Cáceres (Fernández). La tradicional técnica del ganchillo se saca a la calle en formato XXL durante las fiestas del pueblo en formato de parasoles que se cuelgan entre las estrechas calles de la localidad. De nuevo, vemos el paso de los materiales tradicionales de algodón o lana al plástico, más resistente y económico. No es un material tan agradable para trabajar, pero permite que el «quehacer» se saque a la calle y tome una escala paisajística. Los vecinos ahora guardan las bolsas de plástico que usan durante todo el año para tejer y, lo que era un residuo se convierte en el medio por el que ellas, que también tienen presencia residual en la construcción del espacio

Feminismo/s 32, diciembre 2018, pp. 157-179 
público, literalmente toman la calle. Como ocurría en el caso de los indígenas de Brasil, la transformación del «quehacer» material cotidiano es el que transforma el paisaje.

Estos ejemplos muestran el potencial del «quehacer» para llevarnos de la escala cercana a la global. La técnica concreta importa y nos hace emparentarnos de formas distintas con el entorno. Para reforzar esta idea, comentaré un último ejemplo en esta sección. Se trata de un trabajo realizado por el diseñador catalán Curro Claret con personas sin hogar, o que lo han sido, y en colaboración con la Fundación Arrels (Guayabero). Claret diseñó una pieza metálica que puede fabricarse por láser en talleres de tamaño medio que, cada vez más, utilizan la fabricación digital. «La pieza» permite utilizar materiales recogidos en la calle para construir taburetes y otros elementos de mobiliario y ha servido para que estas personas, también descartadas por la sociedad, tengan una segunda oportunidad. Claret insiste en sus presentaciones en que trabajar con estas personas y estas cosas, que estamos acostumbrados a ver rotas por la calle, le ha enseñado lo vulnerables que todos somos en el sistema económico actual. Pero más allá de la crítica, como propone Braidotti, el trabajo que han realizado consigue dar una respuesta ética afirmativa que no sólo nos inspira, aún más, nos da mucho quehacer. «La pieza» no es sólo un diseño fantástico para realizar de forma sencilla uniones complicadas entre materiales dispares, nos abre las puertas a un «quehacer» que cuestiona los paisajes de desecho que construimos con nuestros hábitos de consumo: la posibilidad de reconstruir un nuevo paisaje a partir del paisaje de los despojos urbanos y humanos.

\section{EL PAISAJE TEJIDO DESDE DENTRO}

En la introducción, se comentaba cómo los debates disciplinares en el urbanismo hecho desde el paisaje comparten algunas de estas ideas. Sin embargo, aún no han llegado a definir una práctica que tenga la potencia ética y afirmativa que vemos en estas propuestas. Por ello, para terminar, queremos volver a la hipótesis que se presentaba al principio para, desde el paisaje definido ahora como quehacer con las connotaciones discutidas, responder de forma alternativa a la pregunta de Corner que se introducía al principio del artículo: 
si pudiéramos concebir que la «landscape architecture» fuera un agente activo en el juego de la intervención evolutiva, ¿ cómo tendríamos que interpretar la ecología y la creatividad en la práctica del diseño? (258).

Entendiendo el paisaje como «quehacer», hemos visto que la relación transformadora con el entorno que propone el paisajismo es anterior a la disciplina. Pero, además, con los ejemplos presentados, hemos visto que la relación estética tampoco es patrimonio exclusivo del paisajismo como lo define la disciplina. Así definida, la relación estética implicaba una idea de autoría y autonomía que ya el Landscape Urbanism criticaba (Waldheim 8). El quehacer nos permite pasar de la crítica al activismo con todas sus implicaciones.

Sabemos por la maravillosa explicación de John Habracken (1-30) que el arquitecto es hijo de Palladio, el primer arquitecto que representó el ideal de profesional que Alberti describía en sus libros fundacionales de la disciplina. Como tal, su práctica es heredera de la separación del mundo que suponen la perspectiva y el ejercicio de una profesión liberal. Mientras lo entendamos desde la tradición disciplinar, el paisaje no nos permite ir más atrás en el tiempo que la tradición pictórica, ni más adelante tampoco. El paisaje como «quehacer», en cambio, convierte a las arquitectas en hijas bastardas de Palladio y nos permite explorar la libertad que esto nos da. Donde los arquitectos proponían «marcos» para la acción y para la disciplina (Corner 278), el «quehacer» de Ingold, matizado por Braidotti y Haraway, nos invita a acercarnos a aprender del mundo desde dentro y a soñar posibilidades mientras actuamos en el mundo.

Entonces, ¿cuáles son las implicaciones para la práctica? Proponemos, como el Landscape Urbanism, seguir poniendo la experiencia estética en el centro del trabajo con el paisaje, pero, en lugar de situarnos fuera del mundo, como un pintor renacentista mirando desde un punto de vista fijo, meternos activamente en él, convirtiendo el «quehacer» del diseño en una tarea al servicio del «quehacer» de otras formas de vida, con las que simpatizamos en el propio momento del encuentro estético. Conseguir, como Mary Poppins e Ingold, meternos dentro del cuadro. O, como lo diría Haraway, situarnos.

No es casualidad que todos los «quehaceres» comentados hasta ahora estén relacionados con el tejer. Ya hemos visto que el pensamiento de Ingold está cada vez más relacionado con las líneas, de hecho, ha llegado a proponer que cualquier tipo de práctica, cualquier hacer, es una subcategoría del tejer

Feminismo/s 32, diciembre 2018, pp. 157-179 
(Being alive 211). Una manera de reforzar aún más que el paisaje no es un fondo para la vida: si se quitaran los hilos, no habría nada. Aprendimos la forma más sencilla y bonita de resumir el giro que este «quehacer» supone para el diseño en uno de los talleres liderados por Ingold y Stephanie Bunn y realizados en Aberdeen como parte del Proyecto de Investigación «Knowing From the Inside». En un encuentro de aprendizaje compartido con tejedoras de mimbre, el fantástico artista tejedor Tim Johnson, que ha recorrido el mundo a través del aprendizaje de técnicas de tejido, explicaba su teoría de por qué las técnicas del ganchillo y el punto de dos agujas aparecen y se popularizan en la Época Moderna. En estas técnicas, la estructura del tejido se basa en el entretejido de anillos. La aguja sirve para montar un anillo que se pasa por dentro del anillo anterior. En cambio, en las técnicas más tradicionales que no se han popularizado tanto, el cabo del hilo es el que pasa por dentro del anillo anterior. Para realizar la segunda técnica, el artesano debe ser capaz de hilar además de tejer, pues sería imposible pasar una madeja completa por el anillo anterior. Como veíamos en los ejemplos anteriores, ser capaz de hilar supone una relación productiva con los materiales y los seres que los producen, sea el cultivo de plantas, la cría de ganado, la extracción de recursos como el petróleo o la recogida (ver también el comentario de Haraway sobre las tejedoras Navajo y sus ovejas 'Churro' en Staying 89-95).

En su libro Líneas, una breve historia, Ingold proponía una reflexión sobre cómo las líneas aparecen en la música, el movimiento en el entorno, los tejidos, el lenguaje, el dibujo y otras expresiones humanas, y se hacía la pregunta de cómo sería la antropología si su principal foco de estudio fueran las líneas que todo ser traza al hacer las tareas de su vida. Así definió la idea de malla (meshwork) que Lefebvre introducía en La Producción del Espacio como:

el patrón reticular dejado por animales, salvajes y domésticos, y por la gente (en y alrededor de las casas de una pequeña ciudad o pueblo y en sus entornos cercanos), cuyos movimientos tejen un medio ambiente que es más 'arqui-textural' que arquitectural (Ingold, Lineas 80).

Creemos que, en la práctica del urbanismo, el «quehacer» puede realizar una transformación paralela a la que las líneas produjeron en la antropología de Ingold. Suele ser muy interesante para las artistas, arquitectas y diseñadoras que la antropología de Ingold sea tan gráfica. Pero, si entendemos bien estas líneas como las líneas de «quehacer», vemos que las líneas en que

Feminismo/s 32, diciembre 2018, pp. 157-179 
trabajamos ya no son la lineamenta definida por Alberti. Apoyándose en teóricos de la ciencia y el diseño como David Turnbull (Masons) y Lars Spuybroek (Sympathy), Ingold nos recuerda que estas líneas son abstracciones materiales, trazos que dejan los gestos del arquitecto cuando copia en un patrón, una plantilla o un plano, las formas que toman las fuerzas de los materiales en acción (Making 47-60).

Así entendidas, las líneas de nuestros dibujos ya no son una descripción, sino una manera más de meternos dentro del mundo, como lo es la escritura para Ingold en su relato del cuadro de Bruegel. De hecho, la descripción sería imposible porque el mundo es inacabable. Su tejido, su meshwork, como el quehacer, es fractal. Nos lo explicó Mandelbrot en 1967, al intentar medir la longitud de la costa de Inglaterra: cuanta más atención le prestamos, cuanto más de cerca la dibujamos, más inagotable se hace la vida. El «quehacer» sólo tiene utilidad si lo entendemos como forma de aprendizaje, no de descripción. De nuevo, vemos cómo el practicante activo toma una posición central. El problema del taskscape fue su utilización como un «conjunto de tareas» («Temporality» 158). La palabra quehacer tiene en cambio esa fractalidad que la experiencia cotidiana nos demuestra cuando queremos explicarle a alguien las tareas de cualquier práctica.

Es fácil comprender esto al imaginar lo que nos ocurre cuando intentamos explicarle a alguien la receta de un plato tradicional de nuestro pueblo (o paisaje) a alguien extranjero. Por ejemplo, en nuestro caso, la receta de una paella, a una señora escocesa. No se hace una descripción, pues se emplea un presente orientado hacia el futuro, hacia lo que el otro hará. Necesitamos ponernos en su lugar, en su cocina, con sus cacharros, y se termina detallando no sólo qué tipo de aceite usar y dónde comprarlo, sino también la importancia de preparar la paella en compañía o cómo se debe limpiar después los utensilios para guardarlos. Cuanto más alejada está esa persona de nuestro quehacer cotidiano, más infinita e imposible se vuelve la descripción y más se convierte en una invitación envolvente a experimentar el quehacer que ese plato tradicional recoge, su paisaje. Algo similar a lo que ocurre en los libros de Perec o en la inacabable novela de Gadda, El zafarrancho aquel de Vía Merulana. La maraña que nos sugiere la palabra meshwork da una idea de la inconmensurabilidad del modelo del mundo que propone. Como el Chthulucene de Haraway, la dimensión de la tarea que tenemos por delante

Feminismo/s 32, diciembre 2018, pp. 157-179 
en la transformación de las prácticas del diseño y el paisaje se vuelve casi monstruosa. Quizá lo sea. Quizá por eso, como veíamos en la práctica de los diseñadores y arquitectos que comienzan a tejer parentescos extraños, sólo sea posible realizarla desde el afecto y el deseo.

\section{CONCLUSIONES}

A lo largo del texto hemos introducido las ideas sobre la percepción del paisaje del antropólogo Tim Ingold al idioma español. En los desajustes inevitables de la traducción, se ha hallado un espacio para el encuentro de sus ideas con las de las pensadoras feministas Donna Haraway y Rosi Braidotti que permiten desarrollar el potencial político de ambas en el ámbito del urbanismo hecho desde el paisaje. En este ámbito, el punto de partida es el Landscape Urbanism que, desde los años 90, ya utilizaba el paisaje para incorporar una visión procesual en el urbanismo frente al diseño estático de formas. Sin embargo, la combinación que se expone de la propuesta feminista con la de Ingold va más allá, ofreciéndonos la posibilidad de una práctica del urbanismo enfocada hacia el futuro y hecha desde dentro y junto con las personas y las cosas que desarrollan su vida juntos en el mundo irreversiblemente transformado desde el Antropoceno. El paisaje se entiende como un «quehacer»: la tarea colectiva de reproducción de la vida que tenemos por delante. Para imaginar esta otra práctica disciplinar, se ha seguido el ejemplo de los tres autores y se ha ilustrado con el trabajo de artistas, artesanos, arquitectos y diseñadores con los que se ha conversado, y que se sitúan en el interior de un «quehacer» que es capaz de trabajar cuestiones paisajísticas y territoriales desde la estética entendida como el trabajo material de sus prácticas creativas. Esta conversación, sin embargo, acaba de empezar. Aún queda por delante la exploración del alcance de estas prácticas para la transformación política. No es casualidad que los trabajos discutidos compartan sujetos y prácticas vulnerables y precarizados. Siguiendo con Braidotti, podríamos explorar cómo estas prácticas podrían convertir el urbanismo en una práctica «afirmativa» que descentre el paisaje como objeto de transformación por parte de un autor urbanista, algo que el Landscape Urbanism no incluye en su programa. Aparece así la necesidad de una reflexión crítica sobre cómo podría introducirse y relacionarse este

Feminismo/s 32, diciembre 2018, pp. 157-179 
nuevo «quehacer» del paisajismo en los marcos disciplinares y normativos del urbanismo actual.

\section{REFERENCIAS BIBLIOGRÁFICAS}

Braidotti, Rosi. «Between the No Longer and the Not Yet: Nomadic Variations on the Body», 2000. 23 de enero de 2010. http://www. women. it/cyber archive/ files/braidotti.htm

- Lo Posthumano. Barcelona: GEDISA, 2015.

- Por una política afirmativa: Itinerarios éticos. Barcelona: GEDISA, 2018.

Bruegel, Pieter (el Viejo). La Cosecha (1565). The Metropolitan Museum of Art, Rogers Fund, 1919 (19.164).

Corner, James. The Landscape Imagination: Collected Essays of James Corner, 19902010. First edition. New York: Princeton Architectural Press, 2014.

Fernández-Christlieb, Federico. «El nacimiento del concepto de paisaje y su contraste en dos ámbitos culturales: el viejo y el nuevo mundo». Perspectivas sobre el paisaje Universidad Nacional de Colombia. Ed. Susana Barrera-Lobatón y Julieth Monroy-Hernández. Universidad Nacional de Colombia, 2014. $<$ http://www.uneditorial.com/perspectivas-sobre-el-paisaje-geografia.html>

Fernández Ramos, Marina. «Tejiendo La Calle, arquitectura efímera hecha a mano». Revista PH 0.90 (2016): 10-12.

Gadda, Carlo Emilio. El zafarrancho aquel de vía Merulana. Barcelona: Editorial Arte y Literatura, 1989.

Galí-Izard, Teresa. Los mismos paisajes: ideas e interpretaciones= The same landscapes: ideas and interpretations. Barcelona: Gustavo Gili, 2005.

Gisbert-Alemany, Ester. «An Architecture by Means of Anthropology». [I2] Investigación e Innovación en Arquitectura y Territorio 2.4 (2016). <http:// i2.ua.es/index.php/architecture/article/view/49>

Guayabero, Óscar. Conversación polifónica sobre diseño y otras cosas: Retrato imperfecto de Curro Claret. Barcelona: Gustavo Gili, 2016.

Habraken, N. J. Palladio's Children: Essays on Everyday Environment and the Architect. Oxford: Taylor \& Francis, 2007.

Haraway, Donna J. The companion species manifesto: Dogs, people, and significant otherness. Vol. 1. Chicago: Prickly Paradigm Press, 2003.

- Staying with the Trouble: Making Kin in the Chthulucene. Durham: Duke University Press, 2016. 
Harrison, Paul. «In the Absence of Practice». Environment and Planning D: Society and Space 27.6 (2009): 987-1009. doi:10.1068/d7907.

Helmreich, Stefan. «Listening Against Soundscapes». Anthropology News 51.9 (2010): 10. doi:10.1111/j.1556-3502.2010.51910.x.

Ingold, Tim. «The Temporality of the Landscape». World archaeology 25.2 (1993): 152-174.

- The Perception of the Environment: Essays on Livelihood, Dwelling and Skill. Oxford: Psychology Press, 2000.

- Lineas: una breve historia. Barcelona: Gedisa, 2007.

- Being Alive: Essays on Movement, Knowledge and Description. Oxford: Taylor \& Francis, 2011.

- «The Shape of Land». Landscapes Beyond Land: Routes, Aesthetics, Narratives. Ed. Arnar Árnason, Nicolas Ellison, Jo Vergunst, y Andrew Whitehouse, 197208. Oxford: Berghahn Books, 2012.

- Making: Anthropology, Archaeology, Art and Architecture. Oxford: Routledge, 2013.

- The Life of Lines. Oxford: Routledge, 2015.

- «La creatividad que se experiencia». [i2] Investigación e Innovación en Arquitectura y Territorio 4.2 (2016). doi:10.14198/i2.2016.5.13.

- Anthropology and/as Education. 1 ${ }^{\text {st }}$. edition. Oxford: Routledge, 2017.

— «Taking taskscape to task». Forms of Dwelling: 20 years of Taskscapes in archaeology. Ed. Ulla Rajala y Philip Mills. Oxford: Oxbow Books, 2017. 16-27. <http://www.jstor.org/stable/j.ctt1kw29bw>

Ingold, Tim, Ana Letícia Fiori, José Agnello Alves Dias de Andrade, Adriana Queiróz Testa y Yuri Bassichetto Tambucci. «Diálogos Vagueiros: Vida, Movimento e Antropología. Entrevista com Professor T. Ingold». Ponto Urbe. Revista do núcleo de antropologia urbana da USP 11 (2012).

Janowski, Monica y Tim Ingold. Imagining Landscapes: Past, Present and Future. Oxford: Routledge, 2016.

Jay, Martin. «Scopic Regime». The International Encyclopedia of Communication. Ed. W. Donsbach. American Cancer Society, 2008. doi:10.1002/9781405186407. wbiecs017.

Johnson, Tim. Tim Johnson Artist. 9 diciembre 2018. <http://www.timjohnsonartist.com/>

Lovelock, James. Gaia, a New Look at Life on Earth. Oxford: Oxford University Press, 1979. 
Mandelbrot, Benoit. «How Long Is the Coast of Britain? Statistical Self-Similarity and Fractional Dimension». Science 156.3775 (1967): 636-38.

Manning, Erin. The Minor Gesture. Durham: Duke University Press, 2016.

Mc Harg, Ian. «Diseñar con la Naturaleza». Nueva York: Museo Americano de Historia Natural, 1971.

Noronha, Raquel. «The Collaborative Turn: Challenges and Limits on the Construction of a Common Plan and on Autonomy in Design». Strategic Design Research Journal 11.2 (2018): 125-135-135. doi:10.4013/sdrj.2018.112.08.

Ortega y Gasset, José. «Historia como sistema». Obras completas, Vol. VI. Madrid: Fundación José Ortega y Gasset, 2005.

Perec, Georges. Especies de espacios. Barcelona: Editorial Montesinos, 2003.

- La vida, instrucciones de uso. Barcelona: Anagrama, 2016.

Silla, Rolando Jesús. Tim Ingold, neo-materialismo y pensamiento pos-relacional en antropología. marzo de 2013. <http://ri.conicet.gov.ar/handle/11336/25832> Spuybroek, Lars. The Sympathy of Things: Ruskin and the Ecology of Design. Londres: Bloomsbury Academic, 2016.

Stengers, Isabelle. «Introductory notes on an ecology of practices». Cultural Studies Review 11.1 (2013): 183-196.

Turnbull, David. Masons, Tricksters and Cartographers Makers of Knowledge and Space. Oxford: Harwood Academic, 2000.

Waldheim, Charles. Landscape as Urbanism: A General Theory. Princeton University Press, 2016.

Walsh, Bill, Don DaGradi, Robert Stevenson, Julie Andrews, Dyke D. Van, David Tomlinson, Glynis Johns, Hermione Baddeley, Karen Dotrice, Matthew Garber and Elsa Lanchester. Mary Poppins. Burbank, CA: Distributed by Walt Disney Studios Home Entertainment, 2009.

Wolff, Jane. Delta Primer: A Field Guide to the California Delta. San Francisco: Santa Monica, CA: William K Stout Pub, 2003. 